\title{
Trauma Surgery $\&$ Acute Care Open \\ Laparoscopic cholecystectomy in the Acute Care Surgery model: risk factors for complications
}

\author{
Emily Fletcher, Erica Seabold, Karen Herzing, Ronald Markert, Alyssa Gans, \\ Akpofure Peter Ekeh
}

Department of Surgery, Wright State Physicians, Dayton, Ohio, USA

Correspondence to Dr Akpofure Peter Ekeh, Surgery, Wright State Physicians Department of Surgery, Dayton, OH 45458-9161, USA apekeh@premierhealth.com

Received 19 March 2019 Revised 1 July 2019

Accepted 6 July 2019

\section{ABSTRACT}

Background The Acute Care Surgery (ACS) model developed during the last decade fuses critical care, trauma, and emergency general surgery. ACS teams commonly perform laparoscopic cholecystectomy (LC) for acute biliary disease. This study reviewed LCS performed by an ACS service focusing on risk factors for complications in the emergent setting.

Methods All patients who underwent LC on an ACS service during a 26-month period were identified. Demographic, perioperative, and complication data were collected and analyzed with Fisher's exact test, $\chi^{2}$ test, and Mann-Whitney U Test.

Results During the study period, 547 patients (70.2\% female, mean age $46.1 \pm 18.1$, mean body mass index $32.4 \pm 7.8 \mathrm{~kg} / \mathrm{m}^{2}$ ) had LC performed for various acute indications. Mean surgery time was $77.9 \pm 50.2$ minutes, and $5.7 \%$ of cases were performed "after hours." Rate of conversion to open procedure was $6 \%$. Complications seen included minor bile leaks (3.8\%), infection (3.8\%), retained gallstones $(1.1 \%)$, organ injury $(1.1 \%)$, major duct injury $(0.9 \%)$, and postoperative bleeding $(0.9 \%)$. Statistical analysis demonstrated significant relationships between conversion, length of surgery, age, gender, and intraoperative cholangiogram with various complications. No significant relationships were detected between complications and BMI, pregnancy, attending experience, and time of operation.

Discussion Although several statistically significant relationships were identified between several risk factors and complications, these findings have limited clinical significance. Factors including attending years in practice and time of the operation were not associated with increased complications. ACS services are capable of performing a high volume of LCs for emergent indications with low complication and conversion rates.

Level of evidence:IV

\section{INTRODUCTION}

The Acute Care Surgery (ACS) model is a relatively new concept in surgical care delivery that has become widely popular in the USA in the last decade. ${ }^{1}$ This concept fuses the services of trauma, critical care, and emergency general surgery and has been increasingly adopted by trauma centers. ${ }^{23}$ Right upper quadrant pain arising from biliary etiologies is a common indication for surgical consultation and is within the typical scope of ACS practice. ${ }^{4}$

Laparoscopic cholecystectomy (LC) is a frequently performed operation and is the gold standard for the treatment of many biliary disease processes such as cholelithiasis and cholecystitis. ${ }^{5} 6$ Well-recognized complications of laparoscopic cholecystectomy include bile leak, common bile duct injury, hemorrhage, retained gallstone, and wound infections. ${ }^{7-9}$ Although these complications and associated risk factors have been well studied, limited literature exists evaluating risk factors for perioperative complications in this newer setting of an ACS service, which runs on a team-based concept with changing primary surgeons on call day to day. The aim of this study is to identify demographic and perioperative factors associated with complications of laparoscopic cholecystectomy on a contemporary ACS service.

\section{MATERIALS AND METHODS}

After approval by the Wright State University Institutional Review Board, a retrospective review of an operating room database was used to identify all patients who had undergone LC by the Wright State University Department of Surgery (WSU-DOS) ACS service at Miami Valley Hospital, Dayton, Ohio between January 2014 and February 2016. This hospital is an American College of Surgeons Level I Trauma Center that has used the ACS model since 2005. All patients 18 years of age or older who underwent LC while admitted to the service, for any indication, were included. Patients with planned open cholecystectomy were excluded.

Demographic and perioperative variables were age, gender, body mass index (BMI), pregnancy status, surgical indication, surgical procedure, use of an intraoperative cholangiogram, surgeon years in practice, conversion rate (laparoscopic to open), length of operation, and time of day operation. Attending surgeon experience was stratified as less than 5 years, 5 to 10 years, and greater than 10 years after residency/fellowship training. Time of day of the operation was defined as "daytime" from 07:00 to 19:00 and "after hours" from 19:01 to 06:59. Complications considered were postoperative hemorrhage, bile leak, major bile duct injury, organ injury, infection, and retained stone. Conversion to open cholecystectomy was not considered a complication in this study but rather an indicator of the severity of the patient's disease process. The timeframe for reported complications was 90 days from operation.

Major bile duct injury was defined as an injury to the common bile duct, common hepatic duct, or the right or left hepatic ducts.

Means and SD were reported for continuous variables and counts and percentages for categorical variables. The Mann-Whitney U test was used for comparisons involving two groups and a second 


\begin{tabular}{ll}
$\begin{array}{l}\text { Table } 1 \\
\text { laparoscopic cholecystectomy patients }\end{array}$ \\
\hline Gender, female, \% (n) & $70.2(384)$ \\
\hline Age, years, mean \pm SD & $46.1 \pm 18.1$ \\
\hline BMI, $\mathrm{kg} / \mathrm{m}^{2}$, mean \pm SD & $32.4 \pm 7.8$ \\
\hline Operative indication \% ( $)$ & \\
\hline Acute cholecystitis & $43.3(237)$ \\
\hline Symptomatic cholelithiasis & $28.9(158)$ \\
\hline Chronic cholecystitis & $8.6(47)$ \\
\hline Gallstone pancreatitis & $5.7(31)$ \\
\hline Choledocholithiasis & $4.9(27)$ \\
\hline Biliary dyskinesia & $3.8(21)$ \\
\hline Other & $4.8(26)$ \\
\hline Attending surgeon level of experience, \% (n) & \\
\hline$<5$ years & $8.0(44)$ \\
\hline $5-10$ years & $8.6(47)$ \\
\hline$>10$ years & $83.4(456)$ \\
\hline Time of day of operation, \% (n) & \\
\hline Daytime (07:00-19:00) & $94.3(516)$ \\
\hline After hours (19:01-06:59) & $5.7(31)$ \\
\hline Length of operation, min, mean $\pm S D$ & $77.9 \pm 50.2$ \\
\hline
\end{tabular}

*Other indications included gangrene, cholangitis, gallbladder polyp, pain.

variable measured on a continuous scale. Fisher's exact test or the $\chi^{2}$ test was used to examine the relationship between two categorical variables. Inferences were made at the 0.05 level of significance with no corrections for multiple comparisons. Analyses were conducted using IBM SPSS Statistics V.23.0.

\section{RESULTS}

During the 26-month study period, 547 patients who underwent LC with the ACS service were identified. Demographic and perioperative characteristics are shown in table 1 . The majority of patients were women (70.2\%) with mean age $46.1 \pm 18$ and mean BMI $32.4 \pm 7.8 \mathrm{~kg} / \mathrm{m}^{2}$. Eleven patients (3\%) were pregnant. LCs were performed for the following indications: acute cholecystitis (43.3\%), symptomatic cholelithiasis (28.9\%), chronic cholecystitis $(8.6 \%)$, gallstone pancreatitis $(5.7 \%)$, choledocholithiasis (4.9\%), and biliary dyskinesia (3.8\%).

LC was the sole procedure performed in $76.4 \%$ of the cases whereas $23.6 \%$ of patients had additional procedures (eg, umbilical hernia repair, liver biopsy). Intraoperative cholangiography (IOC) was used in $11.3 \%$ of cases. General surgery residents were involved in all cases and were supervised by one of 11 attending surgeons in the WSU-DOS ACS practice. Most surgeons had more than 10 years of experience $(83.4 \%)$ with $8.6 \%$ having between 5 and 10 years in practice, and $8.0 \%$ having less than 5 years. Mean operative time was $77.9 \pm 50.2$ minutes with only $5.7 \%$ of operations performed "after-hours." Thirty-three (6\%) patients were converted to an open procedure.

Table 2 shows complications within 90 days of the procedure: bile leak (3.8\%); superficial, deep, and intra-abdominal wound infection $(3.8 \%)$; organ injury $(1.1 \%)$; retained stone $(1.1 \%)$; postoperative bleeding (0.9\%); and major bile duct injury $(0.9 \%)$. Organ injuries included uterus, small bowel, and colon injuries associated with entry into the abdomen or dissection. Mortality was $0.4 \%$ with two deaths in the study population, both from septic shock.
Table 2 Complications for 547 laparoscopic cholecystectomy patients

\begin{tabular}{ll}
\hline Complications, \% ( $\mathbf{n})$ & \\
\hline Bile leak & $3.8(21)$ \\
\hline Infection & $3.8(21)$ \\
Retained gallstone & $1.1(6)$ \\
\hline Other organ injury & $1.1(6)$ \\
Postoperative bleeding & $0.9(5)$ \\
\hline Major biliary injury & $0.9(5)$ \\
\hline Mortality, \% (n) & $0.004(2)$ \\
\hline
\end{tabular}

All the bile leaks identified occurred from the cystic duct stump. In all, five patients $(0.9 \%)$ had a major bile duct injury, which were all recognized intraoperatively during the LC, prompting conversion to an open procedure and an immediate repair. Of the six organ injuries (1.1\%) that arose from entry into the abdomen or dissection, all were recognized and addressed immediately except in one case where there was delayed recognition. All other 23 conversions to an open operation were due to the surgeon's clinical decision to convert.

Statistical analysis demonstrated significant relationships between conversion to open cholecystectomy and bile leak $(\mathrm{p}=0.032)$, infection $(\mathrm{p}=0.001)$, organ injury $(\mathrm{p}=0.045)$, bleeding $(p=0.002)$, and major biliary injury $(p=0.002)$. Length of surgery was also associated with multiple complications including bile leak $(p=0.003)$, infection $(p=0.001)$, organ injury $(\mathrm{p}=0.001)$, bleeding $(\mathrm{p}=0.012)$, and major biliary injury $(0.001)$. Surgical procedure type was statistically related to infection $(p=0.015)$, retained gallstone $(p=0.003)$, and organ injury $(p=0.003)$. Utilization of IOC was associated with retained gallstone $(p=0.022)$, gender was associated with postoperative bleeding (0.029), and age was associated with infection $(p=0.004$.). No significant relationships were identified between $\mathrm{BMI}$, pregnancy, attending years in practice or time of day of the operation, and any complications.

\section{DISCUSSION}

Since its advent, the ACS model has demonstrated its suitability for the management of acute biliary disease requiring laparoscopic cholecystectomy. Multiple studies have demonstrated improved timeliness, cost-efficiency, and outcomes for cholecystectomy on ACS services compared with pre-existing traditional general surgery models. ${ }^{10-12}$ The intent of this study was to evaluate the relationship between 11 risk factors and six complications in the setting of an ACS service. Identifying risk factors for complications after LC would permit improved patient selection, preoperative patient optimization, intraoperative surgical decision-making, and postoperative surveillance. This study also sought to determine if this ACS model has resulted in more complications that have traditionally been reported.

The study demonstrated a significant association between multiple complications and conversion rate as well as length of surgery, which is a clinically intuitive finding as one would expect more complicated cases to necessitate conversion more often, require more time, and be prone to more complications. Likewise, the statistical relationship between procedure type and several complications may reflect the need for adjunct procedures, such as lysis of adhesions, enterotomy repair, and common bile duct exploration, in the setting of more complex disease processes. 
At our institution, IOC is selectively used at the discretion of the surgeon based on surgical indication and personal preference; no surgeons in this group routinely used IOC for all LCs. The association between IOC and retained stones may reflect its increased use in cholelithiasis-associated diseases. Additionally, the lack of other significant complications associated with its use supports its utilization on a selective rather than routine basis.

Some of the findings have statistical significance with unclear clinical use. The relationship between gender and postoperative bleeding demonstrated that male patients had increased episodes of postoperative bleeding, though a relatively small proportion of patients in the study group were men (29.8\%). Additionally, a significant association between age and infection was appreciated with infections occurring in an older population. The average age of the population with infections was 56.7 years $( \pm 15.4)$ compared with the patients without infections with average age of 45.7 years $( \pm 18.1)$. At this phase of study, these findings appear to have limited clinical applications.

The study failed to demonstrate significant complication rate associated with factors such as pregnancy or BMI. Surgeon years in practice also were not a significant factor for complications suggesting that LCs are performed just as safely by junior surgeons as by their senior counterparts. The majority of LCs were performed during conventional daytime hours with no increased complications in the small subset performed outside routine hours (19:00 to 06:59) - 5.7\% of cases. Although there is no dedicated "add-on" room at our institution, there is a reasonable mechanism to ensure the vast majority of the cases occur during the day. Regardless, as demonstrated in the results above, there was no difference in complication rate based on the time of day of the operation.

Overall, the aforementioned complication rates in this Acute Care Model are comparable or lower than published on similar study populations. ${ }^{13-15}$

Limitations of this study include its retrospective design, single-site setting, a relatively brief timeframe for the study period (26 months), and a somewhat narrow postoperative follow-up period (90 days). In addition, although 11 important predictors of complications from laparoscopic cholecystectomy were evaluated, other risk factors could have been included. None of the laparoscopic cholecystectomies used single-port or robotic technologies. Also, the study did not assess length of stay, compare the laparoscopic versus open length of operation, cost, or additional sources of morbidity.

\section{CONCLUSIONS}

On our ACS service, LCs are a frequently and safely performed procedure with low complication and conversion rates. Statistical analysis demonstrated 13 statistically significant relationships between various complications and risk factors with either clinically self-evident or of limited clinical significance. ACS services provide an excellent setting for management of acute biliary diseases. As more hospitals look to adopt the ACS model combining trauma care with emergency general surgery, these data provide useful information to assure to the maintenance of quality and low complication rates with the model.
Contributors EF was responsible for study design, data acquisition and interpretation, drafting of article, and work revision. ES and $\mathrm{KH}$ participated in data acquisition, data interpretation, and work revision. RM contributed to analysis and interpretation of data as well as work revision. AG contributed to study design, data interpretation, and work revision. PE was responsible for study concept and design, data interpretation, and work revision.

Funding The authors have not declared a specific grant for this research from any funding agency in the public, commercial or not-for-profit sectors.

Competing interests None declared.

Patient consent for publication Not required.

Provenance and peer review Not commissioned; externally peer reviewed.

Data availability statement All data relevant to the study are included in the article.

Open access This is an open access article distributed in accordance with the Creative Commons Attribution Non Commercial (CC BY-NC 4.0) license, which permits others to distribute, remix, adapt, build upon this work non-commercially, and license their derivative works on different terms, provided the original work is properly cited, appropriate credit is given, any changes made indicated, and the use is non-commercial. See: http://creativecommons.org/licenses/by-nc/4.0/.

\section{REFERENCES}

1. Napolitano LM, Fulda GJ, Davis KA, Ashley DW, Friese R, Van Way CW, Meredith JW, Fabian TC, Jurkovich GJ, Peitzman AB, et al. Challenging issues in surgical critical care, trauma, and acute care surgery: a report from the Critical Care Committee of the American Association for the Surgery of Trauma. J Trauma 2010;69:1619-33.

2. Davis KA, Rozycki GS. Acute care surgery in evolution. Crit Care Med 2010;38(9 Suppl):S405-S410.

3. Santry HP, Madore JC, Collins CE, Ayturk MD, Velmahos GC, Britt LD, Kiefe CI. Variations in the implementation of acute care surgery: results from a national survey of university-affiliated hospitals. J Trauma Acute Care Surg 2015;78:60-7.

4. Pottenger BC, Galante JM, Wisner DH. The modern acute care surgeon: characterization of an evolving surgical niche. J Trauma Acute Care Surg 2015;78:120-5.

5. Sneider EB, Lewis J, Friedrich A, Baratta K, Whitman M, Li Y, Biswas M, Litwin DEM, Cahan MA. Timing and choice of intervention influences outcome in acute cholecystitis: a prospective study. Surg Laparosc Endosc Percutan Tech 2014;24:414-9.

6. Murphy MM, Ng S-C, Simons JP, Csikesz NG, Shah SA, Tseng JF. Predictors of major complications after laparoscopic cholecystectomy: surgeon, hospital, or patient? J Am Coll Surg 2010;211:73-80.

7. Donkervoort SC, Kortram K, Dijksman LM, Boermeester MA, van Ramshorst B, Boerma D. Anticipation of complications after laparoscopic cholecystectomy: prediction of individual outcome. Surg Endosc 2016;30:5388-94.

8. Kaushik R. Bleeding complications in laparoscopic cholecystectomy: incidence, mechanisms, prevention and management. J Minim Access Surg 2010;6:59-65.

9. Triantafyllidis I, Nikoloudis N, Sapidis N, Chrissidou M, Kalaitsidou I, Chrissidis T. Complications of laparoscopic cholecystectomy: our experience in a district general hospital. Surg Laparosc Endosc Percutan Tech 2009;19:449-58.

10. Cubas RF, Gómez NR, Rodriguez S, Wanis M, Sivanandam A, Garberoglio CA. Outcomes in the management of appendicitis and cholecystitis in the setting of a new acute care surgery service model: impact on timing and cost. J Am Coll Surg 2012;215:715-21.

11. Britt RC, Bouchard C, Weireter LJ, Britt LD. Impact of acute care surgery on biliary disease. J Am Coll Surg 2010;210:595-9.

12. Michailidou M, Kulvatunyou N, Friese RS, Gries L, Green DJ, Joseph B, O'Keeffe T, Tang $A L$, Vercruysse $G$, Rhee $P$, et al. Time and cost analysis of gallbladder surgery under the acute care surgery model. J Trauma Acute Care Surg 2014;76:710-4.

13. Lau B, Difronzo LA. An acute care surgery model improves timeliness of care and reduces hospital stay for patients with acute cholecystitis. Am Surg 2011;77:1318-21.

14. Lehane CW, Jootun RN, Bennett M, Wong S, Truskett P. Does an acute care surgical model improve the management and outcome of acute cholecystitis? ANZ J Surg 2010;80:438-42.

15. Pepingco L, Eslick GD, Cox MR. The acute surgical unit as a novel model of care for patients presenting with acute cholecystitis. Med J Aust 2012;196:509-10. 